\title{
Intermolecular Hydrogen Bonding and Vibrational Analysis of $N, N$-Dimethylformamide Hexamer Cluster
}

\author{
Sun-Kyung Park, Kyung-Chul Min, Choongkeun Lee, Soon Kang Hong, ${ }^{\dagger}$ Yunsoo Kim, ${ }^{\ddagger}$ and Nam-Soo Lee \\ Department of Chemistrv, Chungbuk National Chiversit, Cheongin. Chunghuk 361-763. Korea \\ ${ }^{*}$ E-mail: nslee âchungbuk,ackr \\ - Department of Fire Service Administration. Chodang Cniversitu, Chomam 33 4-701. Korea \\ ${ }^{\ddagger}$ Department of Adwanced Materials Chemistry, Korea University, Jochiwon 339-700, Korea \\ Received Julv 16, 2009, Accepted September 10, 2009
}

\begin{abstract}
Hexamer cluster of $N$ indimethylfonmanide(DMF) based on the crystal structure was investigated for the equilibrium structure, the stabilization energies, and the vibrational properties in the density functional force field. The geometry (point group $C_{s}$ ) of fully optimized hexamer clustered DMF shows quite close similarity to the crystal structure weakly intermolecular hydrogen bonded each other. Stretching force constants for intermolecular hy drogen bonded methyl and formyl hydrogen atoms with nearby oxy gen atom, methyl $\mathrm{C}-\mathrm{H} \cdots \mathrm{O}$ and formyl $\mathrm{C}-\mathrm{H} \cdots \mathrm{O}$, were obtained in $0.055 \sim 0.11$ and $\sim 0.081 \mathrm{mdyn} / \AA$, respectively. In-plane bending force constants for hydrogen bonded methyl hydrogen atoms were in $0.25 \sim 0.33$, and for fornyl hydrogen $\sim 0.55 \mathrm{mdy} \AA$. Torsion force constants through hydrogen bonding for methyl hydrogen atoms were in $0.038 \sim 0.089$, and for fomyl hydrogen atom $\sim 0.095 \mathrm{mdyn} \mathrm{A}$. Calculated Raman and infrared spectral features of single and hexamer cluster represent well the experimental spectra of DMF obtained in the liquid state. Noncoincidence between IR and Raman frequency positions of stretching $\mathrm{C}=\mathrm{O}$, formyl $\mathrm{C}-\mathrm{H}$ and other several modes was interpreted in terms of the intermolecular vibrational coupling in the condensed phase.
\end{abstract}

Key Words: N. A-dimetlylformanide. Hexamer cluster. Vibrational analysis, Intermolecular hydrogen bonding. Intermolecular vibrational coupling

\section{Introduction}

DMF ( $\mathrm{N}, \mathrm{N}$-dimethy formamide, $\left.\left(\mathrm{CH}_{3}\right)_{2} \mathrm{NCHO}\right)$ is a hydrophilic aprotic solvent with a high boiling point and very polar with a large dipole moment $3.82 \mathrm{D}$. DMF molecule has a planar skeletal geometry which has been a subject of theoretical computational and experimental investigations over the years. ${ }^{1-8}$ A slight non-planarity in the gas phase was reported by gas phase electron diffraction method." which indicated some attractive intramolecular interaction between oxygen atom and metlyyl hydrogen atom syn to carbonyl group where the distance is quite near, only $2 . \AA$. However. in the liquid or solid state, it was investigated to be planar in the skeletal geometry. In addition. it has some interesting strnictural characters. i.e.. a simplicity in the chemical structure. a low molecular symmetry (point group $C s$ if assuming planar), and an intermolecular interaction capability to its neighbors in the condensed phase considering its physical properties. Geometric configuration of DMF could be qualitatively viewed by considering following resonance forms to explain its distinctive structural feature. a skeletal planarity.

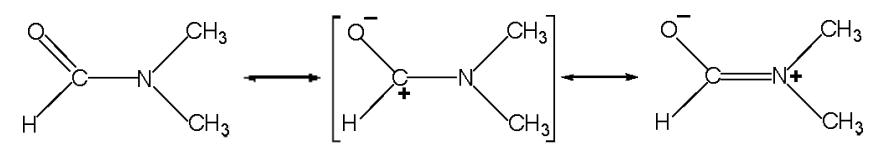

In the liquid state. it is generally considered fully disordered. but a partially ordered stnicture was suggested to form a cluster. possibly a dimer. ${ }^{8}$ The bond length of $\mathrm{C}=\mathrm{O}$ bond $1.2+\mathrm{A}$ in the liquid $^{+}$state obtained through X-ray diffraction study ${ }^{3}$ is slightly. about $0.02 \AA$. longer than in the gas state. while the bond length of fornyl $\mathrm{C}-\mathrm{N}$ bond $1.35 \mathrm{~A}$ in liquid is a bit. about 0.01 $\AA$ longer than in crystal. but $0.04 \AA$ shorter than in the gas state. Others. two methyl $\mathrm{C}-\mathrm{N}$ bonds. $1.45 \AA$, are similar to those in the gas and crystal state. In the crystal structure. the cluster of DMF was formed and connected by weak $\mathrm{C}-\mathrm{H} \cdots \mathrm{O}$ hydrogen bonds, all of which with oxygen atoms as hydrogen bond acceptor. In the crystal structure at $90 \mathrm{~K}$, the mean distance of $\mathrm{C}=\mathrm{O}$ bond was $1.23 \AA$, formyl $\mathrm{C}-\mathrm{N}$ bond $1.3+\mathrm{A}$. and methyl $\mathrm{C}-\mathrm{N}$ bonds $1.453 \AA$. The variance of the bond lengths in different states indicates that a strong intermolecular interaction exercises cooperatively between neighboring molecules in the condensed phases. The structural study ${ }^{1}$ of DMF cry stal and liquid phases showed that the less positively charged formyl proton of DMF in the hexamer cluster allows formation of weak hydrogen bonds in the solid state. which are comparable in strength with interactions between the methyl protons and oxygen atoms.

The intermolecular nonbonding interaction in the condensed phase could be understood to be electrostatic and/or dipoledipole interaction due to its high dipole moment. and other types of weak interactions such as dispersive forces. Among weak interactions, the internolecular hydrogen bonding interaction of $\mathrm{C}-\mathrm{H} \cdots \mathrm{O}$ is known to be very weak, but its existence of this kind of nonbonding ${ }^{8-101}$ was provided specifically in some organic crystal structures. The hydrogen bond distances observed frequently less than $2+\mathrm{A}$ in some crystal structures. Because the van der Waals distance of this bond is near $2.6 \AA$. it could be regarded as a certain amount of hydrogen bonding interaction. Under some circumstances, $\mathrm{C}-\mathrm{H}$ could be a donor 
to form a soft hydrogen bond. It has been focused because this weak nonbonding interaction could be potential in the fields of the supramolecular chemistry and the structural biology of biological macromolecules.

The normal mode analysis is a method based on the analytic dy namics of a chemical system whose potential energy is expressed as a quadratic function. i.e. hannonic potential approximation, of atomic displacement from its equilibrium geometry. A normal mode comes from a concerted motion of interconnected atoms. The nomnal mode analysis of a cluster sy stem can provide direct information of weak nonbonding by way of generating force constants of concerned. This type of low energy interaction has been proven valuable in modeling slow conformational dy namics of biological molecular structures because the force constants of low energy nonbonding interactions should be incorporated for the study of molecular dy namics simulation using empirical force fields at the atomic level.

In the present study, the vibrational analysis of hexamer cluster of six DMF molecules based on the crystal structure ${ }^{1}$ was investigated by the nonmal mode analy sis of Wilson's $G F$ matrix formulation ${ }^{11,12}$ using local symmetry coordinates. We employed the method of density hunctional BP86 approximation which has been successfully applied for the vibrational prediction of many nitrogen compounds because it is more accurate for the vibrational frequency calculations than any other density functional formalism. The polarization and diffuse functions were adapted to consider the significant charge separation in DMF molecules. The calculation results were compared to the experimental spectroscopic Raman or infrared data. The hydrogen bonding effects between neighboring molecules in the hexamer cluster were studied by obtaining the force constants of stretching, bending. and torsion modes as well in energetic and structural points of view.

\section{Computational Details}

Cluster model. Initial structure of cluster was generated using CS CHEM3D PRO (CambridgeSoft Cooperation) according to the crystal structure reported previously and then transferred to the Gaussian03 program package for the optimization and the frequency calculation. Fully optimized structure displayed in Figure 1 was obtained without any structural constraints at various levels of theory and then employed for the calculation of Cartesian force constants and the intensities of Raman and infrared normal modes. The hexamer cluster was not positioned perfectly planar. but slightly tilted holding $C_{\text {, }}$ symmetry as shown in the crystal structure.

Single molecule and hexamer cluster of DMF were calcullated at the theory level of B3LYP and BP86 using the 6-31+ $\mathrm{G}^{* *}$ basis sets with the Gaussian03 program package (Gaussian. Inc.). The isotope atomic masses adapted for calculations were 12.01115 for carbon, 14.00307 for nitrogen, 15.9994 for oxygen. and 1.007825 for hydrogen. respectively. The temperature was set to $298.15 \mathrm{~K}$ and the pressure to $1.0 \mathrm{~atm}$. The infrared and Raman spectra calculated for single and hexamer cluster are shown in Figure 2 along with experimental spectra constructed data taken from ref. 2(a). Because the hexamer cluster possesses its point group $\mathrm{C}_{I}$ słrmmetry the cluster was classified into three

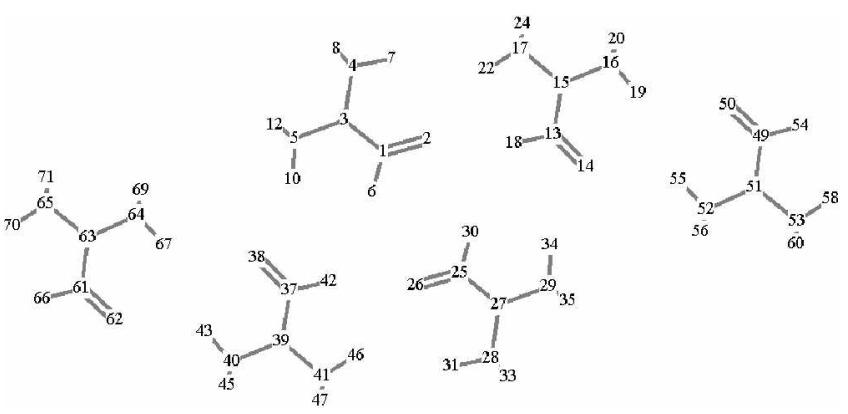

Figure 1. Hexamer cluster of DMF with index numbers and hydrogen bonds between DMF molecules (Dashed lines represent weak hydrogen bonds. ) Cluster was classified into three groups. Group A: index number $1 \sim 12$ and 25 36. Group B: index number $13 \sim 24$ and $37 \sim 48$, Group C: index number $49 \sim 60$ and $61 \sim 72$.

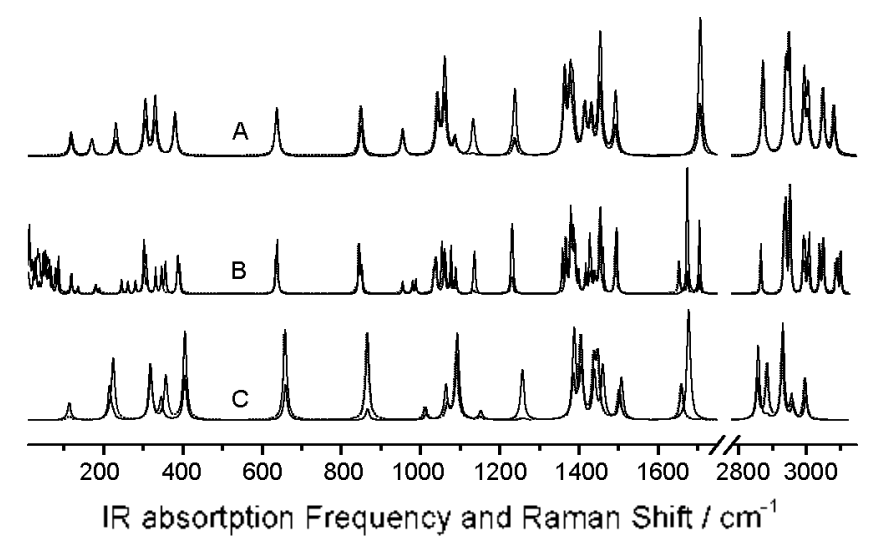

Figure 2. Raman(dot line) and IR(straight line) spectra of DMF. (A: calculated spectra of single DMF, B: calculated spectra of DMF hexamer cluster, C: experimentally observed spectra of liquid state DMF constructed from data presented in ref. $2(a)$.

groups for the convenience. The group $\mathrm{A}$ is of atom index number $1 \sim 12$ and $25 \sim 36$ : the group $B$ of atom index number $13 \sim$ 24 and $37 \sim 48$; the group $C$ of atom index number $49 \sim 60$ and $61 \sim 72$.

Nomal mode analysis. The local symmetry coordinates of single DMF molecule ( $C$ s point group) was composed of 11 stretching. $1+$ in-plane bending. 2 out-of-plane defonmation. and 3 torsion vibrations. These were the same as reported previously: The fundamental vibrational modes are split into $19 \mathrm{~A}^{\prime}$ and $11 \mathrm{~A}^{\prime \prime}$ symmetry species. To obtain vibrational properties of hydrogen bonds in the hexamer cluster ( $C_{2}$ point group). each single molecule was configured to be connected each other through hydrogen bonds displayed in Figure 1. The local symmetry coordinates were composed of 70 stretching. 92 in-plane bending. 12 out-of-plane deformation and 30 torsion vibrations. Single DMF molecule and hexamer cluster have 12 and 72 atoms in total, respectively. The force constants matrix in the Cartesian coordinate generated through density functional calculation has 666 and $23+36$ elements for single molecule and hexamer cluster overall which are conposed of all the diagonal and half the off-diagonal elements. Using these elements, the force constants in the local symmetry coordinates, the frequencies. and potential energy distributions were obtained using 
Table 1. Structural bond lengths in gas, liquid and crystal, and Optinized molecular parameters of DMF single and hexamer cluster at B3LYP and BP86 level of theory.

\begin{tabular}{|c|c|c|c|c|c|c|c|c|c|}
\hline \multirow{3}{*}{ Bond Lengtly/ $\AA$} & \multicolumn{3}{|c|}{ Experimental } & \multicolumn{3}{|c|}{$\mathrm{B} 3 \mathrm{LYP} / 6-31+\mathrm{G} * *$} & \multicolumn{3}{|c|}{$\mathrm{BP} 86 / 6-31+\mathrm{G}^{* *}$} \\
\hline & \multirow{2}{*}{$\mathrm{Gas}^{2}$} & \multirow{2}{*}{ Liquid ${ }^{b}$} & \multirow{2}{*}{ Crystal ${ }^{\circ}$} & \multirow{2}{*}{ single } & \multicolumn{2}{|c|}{ hexamer } & \multirow{2}{*}{ single } & \multicolumn{2}{|c|}{ hexamer } \\
\hline & & & & & Group A, B & Group C & & Group A, B & Group C \\
\hline $\mathrm{C}=\mathrm{O}$ & 1.224 & 1.24 & 1.231 & 1.225 & 1.236 & 1.226 & 1.235 & 1.246 & 1.236 \\
\hline $\mathrm{C}-\mathrm{N}$ & 1.391 & 1.35 & 1.340 & 1.364 & 1.356 & 1.360 & 1.374 & 1.366 & 1.370 \\
\hline $\mathrm{N}-\mathrm{CH}_{2}$ synt to $\mathrm{O}$ & 1.453 & 1.45 & 1.452 & 1.455 & 1.455 & 1.458 & 1.459 & 1.460 & 1.462 \\
\hline $\mathrm{N}-\mathrm{CH}_{2}$ syn to $\mathrm{H}$ & 1.453 & 1.45 & 1.453 & 1.452 & 1.456 & 1.452 & 1.456 & 1.461 & 1.457 \\
\hline $\mathrm{C}-\mathrm{H}$ fonmyl & & 1.09 & 0.980 & 1.106 & 1.101 & 1.106 & 1.117 & 1.112 & 1.117 \\
\hline $\mathrm{C}^{-} \mathrm{H}_{3}$ syn to $\mathrm{O}$ & 1.112 & & 0.950 & 1.090 & 1.089 & 1.089 & 1.100 & 1.099 & 1.099 \\
\hline $\mathrm{C}-\mathrm{H}_{3} \operatorname{syn}$ to $\mathrm{H}$ & & & 0.972 & 1.093 & 1.092 & 1.093 & 1.102 & 1.103 & 1.117 \\
\hline
\end{tabular}

${ }^{a}$ Experimental data from $n f .5$. (unit: $\AA$ ). ${ }^{b}$ Experimental data from $r f . t$. (unit: $\AA$ ). ${ }^{\circ}$ Experimental data from ref. 1 . (unit: $\AA$ ). ${ }^{d}$ group A. B and C classification as shown in Figure 1.

Table 2. Stabilization Energy (k.T/mol) per a DMF molecule at $298 \mathrm{~K}$ and $\mathrm{l}$ atm of Hexamer cluster at B3LYP and BP86 level of theory.

\begin{tabular}{|c|c|c|c|c|}
\hline & Energy $^{\sigma}$ & Single/hartree & Hexamer/hartree & Stabilization ${ }^{6} / \mathrm{kJ} / \mathrm{mol}$ \\
\hline \multirow{3}{*}{ B3. YP/6-31+G** } & $E_{0}$ & -248.431 & -1490.612 & $-10.80(-8.90)$ \\
\hline & $E_{\mathbf{T}}$ & -248.425 & -1490.565 & $-6.42(-5.62)$ \\
\hline & $\Delta \mathrm{G}^{b}$ & -248.431 & -1490.678 & $-40.88(-36.65)$ \\
\hline \multirow{3}{*}{$\mathrm{BP} 86 / 6-\hat{3} \mathrm{l}+\mathrm{G}^{* *}$} & $E_{0}$ & -248.431 & -1490.603 & $-7.58(-6.46)$ \\
\hline & $E_{\mathbf{T}}$ & -248.425 & -1490.555 & $-3.18(-2.82)$ \\
\hline & $\Delta G^{b}$ & -248.431 & -1490.670 & $-38.11(-33.45)$ \\
\hline
\end{tabular}

${ }^{a} \mathrm{E}_{s}$ (electronic + zero point energy) and $\mathrm{E}_{\mathrm{T}}$ (electronic + themal energy) $=\Delta \mathrm{H}^{b}$ Vibrational entropy was only counted. so the rotational and translational entropy were ignored for the Gibbs free energy calculation. "The stabilization energies $\Delta\left(E_{c}\right), \Delta\left(E_{T}\right)$ and $\Delta(\Delta G)$ are in $k$. I mol unit. and defined as [ $\Delta$ (hexamer)- $6 \Delta$ (single)] 6 . The values in parenthesis are the stabilization energies abtained from the counterpoise corrected calculation for the superposition errors in the basis set (BSSE).

Wilson`s GF matrix method. In this study, we did not apply any scaling factor e.g. 0.96 etc. for the frequency calculations partly because the intermolecular interaction and dipolar coupling in the hexamer cluster adjust and/or affect the whole stnictural parameters of molecules. Others were the same as previously reported.

\section{Results and Discussion}

Optimized structure of DMF hexamer cluster. Mean bond distances of fully optimized geometry of DMF hexamer cluster at the level of B3LYP and BP86 theory using $6-31+\mathrm{G}^{* *}$ basis set have been presented in Table I with those of fully optimized DMF single. Gas. liquid and X-ray crystallographic data of crystal state were included. Every DMF single molecule in the cluster was planar in the optimized geometry as well as in the single molecule. The skeletal inter-planar angle for hexamer was obtained to have $178.1^{\circ}$ at B3LYP level and $178.7^{\circ}$ at BP86 level. This angle is similar to the crystal geometry. where the angle of $170.9^{\circ}$ was observed. ${ }^{l}$

The carbonyl bond length varies upon the physical state of DMF as much $0.01 \AA$ A. i.e.. $1.22 \AA$ (gas). $1.24 \AA$ (liquid) and $1.23 \AA$ (crystal). Further the bond length of $\mathrm{C}-\mathrm{N}$ connected next to carbonyl group decrease upon the states. $1.39 \AA$ (gas). $1.35 \AA$ (liquid) and $1.3+\AA$ (crystal). The bond lengths $\mathrm{C}-\mathrm{H}$ of formyl and methyl groups also decrease on the states. $1.112 \mathrm{~A}$ (gas), $1.09 \AA$ (liquid) and $20.98 \AA$ (crystal). The lengthening of $\mathrm{C}=\mathrm{O}$, shortening of both $\mathrm{C}-\mathrm{N}$ and $\mathrm{C}-\mathrm{H}$ bond distances in the condensed phase indicate the strong intermolecular interaction. In the calculated geonetry, the same features were observed. but not as much as the experimentally observed stnuctural. However. the four-membered centro-symmetric ring entity (group A and B in Table 1 and Figure 1) inside the hexamer cluster shows above experimental measures clearly. The bond lengths of $\mathrm{C}-\mathrm{H}$ in cry stal are noticeably shorter than liquid or gas partly because the distance of hydrogen atom inherently comes shorter through the crystal packing.

Energetics of DMF hexamercluster. Intermolecular interactions would generate significant stabilization energies to form the cluster. Table 2 shows these results at two levels of theory. B3LYP and BP86 using 6-31+G** basis set under 1.0 atm and $298 \mathrm{~K}$. Because clustering could generate a lot of low frequencies from concerted vibrational motions in the cluster. the vibrational contribution becone larger upon more clustering. These low vibrational frequencies generated due to clustering shows two different effects. i.e.. moderate stabilization in enthalpy (or internal energy) and large stabilization in free energy. The thermal correction of vibrational component to the internal energy. $\Delta \mathrm{U}_{\mathrm{vib}}(\mathrm{T})$, would be quite large for clustering due to considerable contribution of low frequencies. It would 
Table 3. Calculated Frequencies of DMF single and hexamer at BP86 level, and experimental Raman and infrared frequencies of liquid DMF with Assigmments.

\begin{tabular}{|c|c|c|c|c|c|c|}
\hline & \multicolumn{2}{|c|}{ Experimental } & \multirow{2}{*}{$\begin{array}{l}\text { DMF } \\
\text { single }\end{array}$} & \multicolumn{2}{|c|}{ DMF hexamer } & \multirow{2}{*}{ Assignments $^{d}$} \\
\hline & Ramann $^{b}$ & $\mathrm{IR}^{b}$ & & Raman $^{c}$ & $\mathrm{IR}^{c}$ & \\
\hline$v^{\prime}$ & 2996 & 2998 & 3081 & $3086(\mathrm{~A}), 3092(\mathrm{C}), 3101(\mathrm{~B})$ & $3086(\mathrm{~A}), 3092(\mathrm{C}), 3101(\mathrm{~B})$ & $r_{38}^{\prime}\left(\mathrm{CH}_{3}\right)^{0}$ \\
\hline$\sqrt{2}$ & 2960 & 2956 & 3050 & $3039(\mathrm{~A}), 3047(\mathrm{C}), 3051(\mathrm{~B})$ & $3039(\mathrm{~A}), 3047(\mathrm{C}), 3051(\mathrm{~B})$ & $v_{a \dot{s}}\left(\mathrm{CH}_{3}\right)^{\mathrm{H}}$ \\
\hline$\sqrt{3}$ & 2929 & 2930 & 2950 & $2951(\mathrm{~A}), 2952(\mathrm{C}), 2954(\mathrm{~B})$ & $2951(\mathrm{~A}), 2952(\mathrm{C}), 2954(\mathrm{~B})$ & $r_{5}\left(\mathrm{CH}_{3}\right)^{\circ}$ \\
\hline$\sqrt{4}$ & 2884 & 2884 & 2940 & $2935(\mathrm{~A}), 2937(\mathrm{~B}), 2940(\mathrm{C})$ & $2934(\mathrm{~A}), 2937(\mathrm{~B}), 2940(\mathrm{C})$ & $v_{2}\left(\mathrm{CH}_{3}\right)^{\mathrm{H}}$ \\
\hline$\sqrt{5}$ & 2856 & 2857 & 2872 & $2867(\mathrm{C}), 2933(\mathrm{~B}), 29+1(\mathrm{~A})$ & $2867(\mathrm{C}), 2933(\mathrm{~B}), 2938(\mathrm{~A})$ & I(Cl-H) \\
\hline$\sqrt{6}$ & 1659 & 1677 & 1707 & $1654(\mathrm{~A}), 1674(\mathrm{~B}), 1705(\mathrm{C})$ & $1673(\mathrm{~A}), 1674(\mathrm{~B}), 1705(\mathrm{C})$ & $v(\mathrm{C}=\mathrm{O})+v(\mathrm{Cl}-\mathrm{N})$ \\
\hline$\sqrt{7}$ & 1502 & 1507 & 1493 & $1492(\mathrm{~A}), 1494(\mathrm{C}), 1496(\mathrm{~B})$ & $1493(\mathrm{C}), 1494(\mathrm{~A}), 1496(\mathrm{~B})$ & $\widehat{\delta}_{a s}\left(\mathrm{CH}_{3}\right)^{\mathrm{H}}+\widehat{\delta}_{a s}\left(\mathrm{CH}_{3}\right)^{\mathrm{a}}$ \\
\hline 18 & 1448 & 1460 & 1455 & $1453(\mathrm{~A}), 1454(\mathrm{~B}), 1455(\mathrm{C})$ & $1453(\mathrm{~A}), 1454(\mathrm{~B}), 1455(\mathrm{C})$ & $\delta_{a r}\left(\mathrm{CH}_{3}\right)^{0}+\delta_{\mathrm{ak}}\left(\mathrm{CH}_{3}\right)^{\mathrm{H}}$ \\
\hline 19 & 1438 & 1440 & 1416 & $1417(\mathrm{C}), 1427(\mathrm{~B}), 1428(\mathrm{~A})$ & $1417(\mathrm{C}), 1427(\mathrm{~B}), 1428(\mathrm{~A})$ & $\delta_{s}\left(\mathrm{CH}_{3}\right)^{\mathrm{H}}$ \\
\hline$v 10$ & 1405 & 1406 & 1386 & $1379(\mathrm{~B}), 1380(\mathrm{~A}), 1391(\mathrm{C})$ & $1379(\mathrm{~B}), 1380(\mathrm{~A}), 1391(\mathrm{C})$ & $\delta_{s}\left(\mathrm{CH}_{3}\right)^{\prime}+\not{\alpha}(\mathrm{C}-\mathrm{H})$ \\
\hline vll & 1386 & 1388 & 1378 & $1381(\mathrm{C}), 1385(\mathrm{~B}), 1389(\mathrm{~A})$ & $1381(\mathrm{C}), 1385(\mathrm{~B}), 1389(\mathrm{~A})$ & $\checkmark(\mathrm{Cl}-\mathrm{N})+\delta_{8}\left(\mathrm{CH}_{3}\right)^{\mathrm{H}}$ \\
\hline$v 12$ & 1386 & 1388 & 1364 & $1367(\mathrm{~A}), 1368(\mathrm{C}), 1400(\mathrm{~B})$ & $1358(\mathrm{~A}), 1368(\mathrm{C}), 1400(\mathrm{~B})$ & $\delta(\mathrm{C}-\mathrm{H})+r(\mathrm{~N}-\mathrm{C} 4)$ \\
\hline$v 13$ & & 1257 & 1239 & $1229(\mathrm{~B}), 1232(\mathrm{C}), 1233(\mathrm{~A})$ & $1229(\mathrm{~B}), 1232(\mathrm{C}), 1233(\mathrm{~A})$ & $v(\mathrm{~N}-\mathrm{C} 5 \mathrm{j}+v(\mathrm{~N}-\mathrm{C} 4)$ \\
\hline rlt & 1091 & 1093 & 1062 & $1040(\mathrm{~A}), 1060(\mathrm{C}), 1076(\mathrm{~B})$ & $1040(\mathrm{~A}), 1060(\mathrm{C}), 1077(\mathrm{~B})$ & $\rho\left(\mathrm{CH}_{3}\right)^{\mathrm{H}}+\rho\left(\mathrm{CH}_{3}\right)^{\mathrm{O}}$ \\
\hline$v 15$ & 1068 & 1064 & 1043 & $1034(\mathrm{~B}), 1038(\mathrm{C}), 1054(\mathrm{~A})$ & $1034(\mathrm{~B}), 1038(\mathrm{C}), 1063(\mathrm{~A})$ & $\rho\left(\mathrm{CH}_{3}\right)^{\mathrm{O}}+\rho\left(\mathrm{CH}_{3}\right)^{\mathrm{H}}$ \\
\hline$v 16$ & 866 & 866 & 851 & $845(\mathrm{C}), 847(\mathrm{~B}), 852(\mathrm{~A})$ & $845(\mathrm{C}), 847(\mathrm{~B}), 852(\mathrm{~A})$ & $\mathrm{r}(\mathrm{N}-\mathrm{C} 4)+\mathrm{N}-\mathrm{N}-\mathrm{C})$ \\
\hline$v 17$ & 658 & 659 & 638 & $636(\mathrm{~A}), 638(\mathrm{C}), 639(\mathrm{~B})$ & $634(\mathrm{~A}), 638(\mathrm{C}), 640(\mathrm{~B})$ & $\partial(O C N)+v(N-C 5)$ \\
\hline$v 18$ & 405 & 405 & 380 & $387(\mathrm{~A}), 388(\mathrm{C}), 392(\mathrm{~B})$ & $387(\mathrm{~A}), 388(\mathrm{C}), 392(\mathrm{~B})$ & $\delta(\mathrm{C}+\mathrm{NC} 5)$ \\
\hline$v 19$ & 319 & 318 & 305 & $302(\mathrm{C}), 304(\mathrm{~B}), 310(\mathrm{~A})$ & $302(\mathrm{C}), 303(\mathrm{~B}), 307(\mathrm{~A})$ & $\partial(\mathrm{ClNC} 5)+\partial(\mathrm{OCN})$ \\
\hline 20 & 2996 & 2998 & 3005 & $3005(\mathrm{~A}), 3009(\mathrm{~B}), 3009(\mathrm{C})$ & $3005(\mathrm{~A}), 3009(\mathrm{~B}), 3009(\mathrm{C})$ & $\gamma_{g s}^{\prime}\left(\mathrm{CH}_{3}\right) o p^{\circ}$ \\
\hline$\sqrt{21}$ & 2960 & 2956 & 2993 & $2951(\mathrm{~A}), 2952(\mathrm{C}), 2954(\mathrm{~B})$ & $2951(\mathrm{~A}) .2952(\mathrm{C}) .2954(\mathrm{~B})$ & $v_{\mathrm{As}}\left(\mathrm{CH}_{3}\right) \mathrm{op}^{\mathrm{H}}$ \\
\hline$\sqrt{22}$ & 1448 & 1460 & 1454 & $1453(\mathrm{~B}), 1457(\mathrm{~A}), 1461(\mathrm{C})$ & $1454(\mathrm{~B}), 1457(\mathrm{~A}), 1462(\mathrm{C})$ & $\delta_{\mathrm{ar}}\left(\mathrm{CH}_{3}\right) \mathrm{op}^{\mathrm{C}}$ \\
\hline$\sqrt{23}$ & 1438 & 1439 & 1431 & $1432(\mathrm{C}), 1439(\mathrm{~B}), 1444(\mathrm{~A})$ & $1432(\mathrm{C}), 1439(\mathrm{~B}), 1444(\mathrm{~A})$ & $\delta_{3}\left(\mathrm{CH}_{3} \mathrm{op}^{\mathrm{H}}\right.$ \\
\hline$\sqrt{24}$ & & 1152 & 1133 & $1135(\mathrm{C}), 1137(\mathrm{~B}), 1138(\mathrm{~A})$ & $1135(\mathrm{C}), 1137(\mathrm{~B}), 1138(\mathrm{~A})$ & $\rho\left(\mathrm{CH}_{3}\right) \rho p^{\circ}+\rho\left(\mathrm{CH}_{3}\right) o p^{\mathrm{H}}$ \\
\hline$\sqrt{25}$ & 1091 & 1093 & 1087 & $1089(\mathrm{C}), 1090(\mathrm{~A}), 1090(\mathrm{~B})$ & $1089(\mathrm{C}), 1090(\mathrm{~A}), 1090(\mathrm{~B})$ & $\rho\left(\mathrm{CH}_{3}\right) \rho p^{\mathrm{H}}+\rho\left(\mathrm{CH}_{3}\right) \rho p^{\circ}$ \\
\hline$v 26$ & 1012 & 1014 & 956 & $955(\mathrm{C}), 980(\mathrm{~A}), 989(\mathrm{~B})$ & $955(\mathrm{C}), 980(\mathrm{~A}), 989(\mathrm{~B})$ & $\delta(\mathrm{C}-\mathrm{H}) \mathrm{op}$ \\
\hline 27 & 357 & 345 & 330 & $332(\mathrm{C}), 346(\mathrm{~B}), 350(\mathrm{~A})$ & $332(\mathrm{C}), 346(\mathrm{~B}), 356(\mathrm{~A})$ & $\pi(\mathrm{Cl}-\mathrm{N} 3)$ \\
\hline$v 28$ & 224 & & 232 & $246(\mathrm{C}), 261(\mathrm{~B}), 28 \mathrm{l}(\mathrm{A})$ & $246(\mathrm{C}), 261(\mathrm{~B}), 281(\mathrm{~A})$ & $\tau(\mathrm{N} 3-\mathrm{C} 5)+\delta(\mathrm{CNC}) \mathrm{pp}$ \\
\hline 29 & & 215 & 171 & $179(\mathrm{~A}), 182(\mathrm{C}), 190(\mathrm{~B})$ & $180(\mathrm{~A}), 182(\mathrm{C}), 190(\mathrm{~B})$ & $\tau(\mathrm{N} 3-\mathrm{C} 5)+\delta(\mathrm{N} 3-\mathrm{C} 4)$ \\
\hline$\sqrt{30}$ & & 113 & 118 & $118(\mathrm{~A}), 120(\mathrm{C}), 136(\mathrm{~B})$ & $118(\mathrm{~A}), 120(\mathrm{C}), 136(\mathrm{~B})$ & $\delta(\mathrm{CNC}) \mathrm{pp}+\tau(\mathrm{N} 3-\mathrm{C} 4)$ \\
\hline
\end{tabular}

"Vibrations $\mathrm{vl} \sim \mathrm{v} 19$; A' svmmetry, vibrations $v 22 \sim \mathrm{v} 30$ : A" svmmetry in DMF single. "Experimental data taken from ref. 2(a). "The band pairs in which the vibrational coupling occurs noticeably are typed in the bold face. "symbol $v$ ": stretching. $\delta$ : deformation, $\rho$ : rocking. $\tau$ : torsion. op: out-of-skeletal plane. subscript s: symmetric. subscript as: anti-symmetric. superscript $\mathrm{O}$ : syn to oxygen atom. superscript $\mathrm{H}$ : syn to formyl $\mathrm{H}$ atom.

increase the total internal energy of the cluster. consequently the total enthalpy. which results in moderate stabilization in enthalpy. However, these low frequencies increase also the total entropy a great deal to derive the free energy considerably low. Considering the stabilization in a condensed phase. the contributions of rotational and translational entropy to total entropy were ignored for the total free energy. Therefore the vibrational entropy was only counted to obtain the Gibbs free energy as following formulas.

$$
\begin{aligned}
\Delta \mathrm{H}= & \Delta \mathrm{U}+\Delta(\mathrm{PV})=\mathrm{E}_{\diamond}+\Delta \mathrm{U}(\mathrm{T})+\Delta(\mathrm{PV}) \cong \mathrm{E}_{\diamond}+\Delta \mathrm{U}(\mathrm{T})=\mathrm{E}_{\mathrm{T}} \\
& \mathrm{E}_{\mathrm{o}}=\text { electronic }+ \text { zero point energy } \\
& \mathrm{E}_{\mathrm{T}}=\text { electronic }+ \text { thermal energy } \\
& \Delta \mathrm{U}(\mathrm{T})=\Delta \mathrm{U}_{\text {tran }}(\mathrm{T})+\Delta \mathrm{U}_{\mathrm{vo}}(\mathrm{T})+\Delta \mathrm{U}_{\mathrm{vib}}(\mathrm{T})
\end{aligned}
$$

$$
\begin{aligned}
& \Delta \mathrm{G}=\Delta \mathrm{H} \cdot \mathrm{T} \Delta \mathrm{S}_{\mathrm{cit}} \\
& =\Delta \mathrm{H}-\mathrm{T} \Delta\left(\mathrm{S}_{\mathrm{rans}}+\mathrm{S}_{\mathrm{rot}}+\mathrm{S}_{\mathrm{v} \mathrm{b}}+\ldots\right) \cong \Delta \mathrm{H}-\mathrm{T} \Delta\left(\mathrm{S}_{\mathrm{v} \mathrm{b}}+\ldots\right)
\end{aligned}
$$

Stabilization energies in $\Delta H$ ( $\cong E_{T}$ in a condensed phase) per a single DMF molecule was. as expected. calculated in the range of about $-5 \mathrm{~kJ} / \mathrm{mol}$ for hexamer. However, the stabilization free energy $\Delta G$ was obtained to be about $-40 \mathrm{~kJ} / \mathrm{mol}$ as shown in Table 2 . If we consider the lager cluster. the stabilization free energies would be greater even.

Vibrational analysis of DMF hexamer cluster: Calculated infrared and Raman spectra of DMF single and hexamer cluster at BP86/6-31+G** level with experimental frequencies of liquid DMF in Figure 2 and Table 3 . The band pairs in which the intermolecular vibrational coupling occurs noticeably are 
typed in the bold face. The frequency results of B3LYP functional were not good enough for the analy'sis. so those of BP86 functional were analyzed. Normal mode analy'sis of single DMF molecule had been extensively studied previously by several groups. and every mode of its 30 normal modes had been well defined. Our results for single DMF were the same as previous studies.

Vibrations of $\mathbf{C}=\mathbf{O}$ stretching region: The characteristic feature of an amide species is the amide I band. which is mainly attributed to $\mathrm{C}=\mathrm{O}$ stretching and associated with $\mathrm{C}-\mathrm{N}$ stretching and weakly with $\mathrm{C}-\mathrm{H}$ in-plane bending. Stretching frequencies (v6) of $\mathrm{C}=\mathrm{O}$ were calculated at $1654 \mathrm{~cm}^{-1}$ in Raman and at $1673 \mathrm{~cm}^{-1}$ in $\mathbb{R}$ for group $A$ of the hexamer cluster. For group B and C. they show at 1674 and $1705 \mathrm{~cm}^{-1}$. respectively: They are all well below down-shifted compared to amide I band of isolated DMF. Amide I band of isolated DMF in the liquid phase ${ }^{13}$ was measured at $1724 \mathrm{~cm}^{-1}$ by diluting DMF in $\mathrm{CCl}_{4}$ solution. In addition, considering they are spread in three parts. these three groups show different extent of perturbation for their potential curves induced from their own intermolecular interactions.

For group A two carbonyll bonds couples strongly because they are near each other oppositely facing in parallel and very polar. As a consequence the in-phase (Raman active) and out-of-phase stretching (IR active) mode shows positive noncoincidence effect $(\mathrm{NCE}) .^{14-18}$ in this case $\Delta \omega=19 \mathrm{~cm}^{-1}$. This effect is known to be as $\Delta \omega=\omega_{\text {ay3 }}-\omega_{180} \cong \omega_{11}-\omega_{130}$ because the IR peak frequencies are approximately coincident with the anisotropic Raman lines. ${ }^{1+}$ The intensity of isotropic Raman line is much higher than anisotropic for the polarized Raman lines. This value is quite comparable to $17 \mathrm{~cm}^{-1}$ calculated with a time-domain computation method. ${ }^{18}$ Delocalization of vibrational energy or splitting of a degenerated vibrational level for a certain mode by means of vibrational coupling ${ }^{19-1}$ are often considered by two kinds of mechanism. i.e.. couplings through bond and through space. This NCE observed in group A is almost completely through the space coupling due to intermolecular coupling of dipolar bonds. The effect through bond is weak compared to through space as can be seen in following table which is from BP8 $6 / 6-31+\mathrm{G}^{* *}$ calculation of hexamer cluster.
0.1 or less. For group C, the diagonal force constants of in-phase and out-of-phase mode are not much different. indicating the coupling is very weak. The mixing between group $\mathrm{A}$ and $\mathrm{C}$ would be very weak partly because of their positional effect, nearly anti-parallel and far apart. Between group B and C. they couple in moderate way because they are in parallel. still very small due to orientation angle dependence of two dipolar interactions in parallel, $\left(1-3 \cos ^{2} \theta\right.$, angle $\theta=52.8$ degree between two parallel carbonyl groups of group $B$ and $C$ ). Between group $A$ and $B$. small extent of mixing occurs in the in-phase stretching vibrations, but weak enough in the out-of-phase stretching vibrations. The diagonal force constants of group A. inphase (10.7946 mdy $/ \AA$ ) and out-of-phase (10.9222 $\mathrm{mdyn} / \AA)$ of $\mathrm{C}=\mathrm{O}$ stretching vibrations show considerable difference for the most part responsible for positive high NCE.

Vibrations of formyl C-H stretching and deformation region: Stretching frequencies ( $v 5$ ) of formyl C-H show a splitting at $2941 \mathrm{~cm}^{-1}$ in Raman in-phase node and at $2938 \mathrm{~cm}^{.3}$ in IR out-of-phase for group $A$. whereas no splitting both for group $B$ at $2933 \mathrm{~cm}^{-1}$ and for group C at $2867 \mathrm{~cm}^{-1}$. In this case. the NCE value $\Delta \omega$ is small and negative value, $-3 \mathrm{~cm}^{-1}$. Because $\mathrm{C}-\mathrm{H}$ bond is weakly dipolar, the extent of intermolecular coupling is expected to be very small. It was proposed that when liquid stnuctures are dominated by non-polar forces as those present in $\mathrm{H}$-bonded liquids (as $\mathrm{C}-\mathrm{O}$ stretching mode ${ }^{17}$ of methanol) the $\mathbb{R}$ active modes may give rise to negative NCE. The delocalization of vibrational energy' in the repulsive potential region caused by steric repulsive interactions (such as ring breathing mode of bemzene) results in the negative non-coincidences. On the other hand. the resonance energy transfer arising due to the transition dipole-dipole (and induced dipoleinduced dipole) interactions causes mainly positive noncoincidence (as $\mathrm{O}-\mathrm{H}$ stretching mode of methanol, carbonyl of acetone $e^{15}$ or amide I of peptide. ${ }^{2 i} e t c$ ). This small and negative value. $-3 \mathrm{~cm}^{-1}$ observed in the fornyl $\mathrm{C}-\mathrm{H}$ stretching of group A seems to be caused by steric repulsive interactions because this stretching is mixed weakly in the intramolecular manner with $\mathrm{C}-\mathrm{H}_{3}$ stretching syn to formyl hydrogen atoms and in the intermolecular manner with formyl hydrogen atoms of group $B$.

The blue-shift of stretching frequency of $\mathrm{X}-\mathrm{H}$ caused by intra/intermolecular interactions as $\mathrm{X}-\mathrm{H} \cdots \mathrm{Y}$ types has been

\begin{tabular}{|c|c|c|c|c|c|c|}
\hline $\begin{array}{l}C=O \text { stretching force } \\
\text { constant ( unit: mdyn } / A \text { ) }\end{array}$ & $\begin{array}{l}\text { Group A } \\
\text { in-phase }\end{array}$ & $\begin{array}{l}\text { Group B } \\
\text { in-phase }\end{array}$ & $\begin{array}{l}\text { Group C } \\
\text { in-phase }\end{array}$ & $\begin{array}{l}\text { Group A } \\
\text { out-of-phase }\end{array}$ & $\begin{array}{l}\text { Group B } \\
\text { out-of-phase }\end{array}$ & $\begin{array}{l}\text { group C } \\
\text { out-of-phase }\end{array}$ \\
\hline group A in-phase & 10.7946 & & & & & \\
\hline group B in-phase & -0.1105 & 10.8393 & & & & \\
\hline group C in-phase & 0.0130 & -0.0284 & 11.4331 & & & \\
\hline group A out-of-phase & & & & 10.9222 & & \\
\hline group B out-of-phase & & & & 0.0120 & 10.8715 & \\
\hline group C out-of-phase & & & & 00039 & -0.0346 & 11.4345 \\
\hline
\end{tabular}

The in-phase and out-of-phase $\mathrm{C}=\mathrm{O}$ stretching vibrations of group A. B and $\mathrm{C}$ in the diagonal elements show very large values of force constants near in the range of $10 \sim 11 \mathrm{mdy} n / \AA$ as shown in table above. In contrast. the interaction force constants in the off-diagonal elements are relatively small. about well studied and reported as the improper blue-shifting hydrogen bond. ${ }^{22-24}$ The structural change of DMF induced by the water hydrogen bonded on the carbonyl group has been exclusively studied responsible for the methyl $\mathrm{C}-\mathrm{H}$ blue-shift. ${ }^{25-28}$ Taking a look at only calculated results for single and hexamer. 
Table 4. Optimized structural parameters and Calculated force constants in the local symmetry coordinates ( $m d y n / A$ for stretching, and mdyn $\AA$ for bending or torsion of intennolecular hydrogen bonding in DMF hexamer cluster at B3LYP and BP86 level.

\begin{tabular}{|c|c|c|c|c|c|c|}
\hline & \multirow{2}{*}{ Atoms $^{a}$} & \multirow{2}{*}{$\frac{\text { Experimental }}{\text { Crystal }^{b}}$} & \multicolumn{2}{|c|}{ B3LYP/6-31+G** } & \multicolumn{2}{|c|}{$\mathrm{BP} 86 / 6-31+\mathrm{G}^{* *}$} \\
\hline & & & Strulctures & Force Constant & Structure & Force Constant \\
\hline \multirow{4}{*}{ Stretching } & $\mathrm{r}(\mathrm{H} 18 \cdots \mathrm{O} 2)$ & $2.418 \AA$ & 2.380 & 00906 & 2.399 & 0.0810 \\
\hline & $\mathrm{r}(\mathrm{O} 14 \cdots \mathrm{H} 55)$ & $2.647 \AA$ & 2.520 & 0.0759 & 2.573 & 0.0550 \\
\hline & $\mathrm{r}(\mathrm{H} 43 \cdots \mathrm{O} 62)$ & & 2.480 & 00919 & 2.503 & 0.0693 \\
\hline & $\mathrm{r}(038 \cdots \mathrm{Hl} 10)$ & $2.446 \AA$ & 2.322 & 0.1113 & 2.305 & 0.1084 \\
\hline \multirow{4}{*}{ Bending } & $\theta(2,18,13)$ & $149.3^{\circ}$ & 167.21 & 0.5267 & 164.56 & 0.5514 \\
\hline & $\theta(14,55,52)$ & $144.7^{\circ}$ & 142.09 & 0.3264 & 141.05 & 0.2886 \\
\hline & $\theta(62,43,40)$ & & 140.84 & 0.4035 & 138.77 & 0.3300 \\
\hline & $\theta(38,10,5)$ & $167.3^{\circ}$ & 158.29 & 0.2764 & 157.39 & 0.2553 \\
\hline \multirow{4}{*}{ Torsion } & $\tau(1,2,18,13)$ & $170.9^{\circ}$ & 178.05 & 0.0723 & 178.69 & 0.0957 \\
\hline & $\tau(1 \hat{3}, 14,55,52)$ & & -178.02 & 00384 & 176.32 & 00403 \\
\hline & $\tau(61,62,43,40)$ & & 178.78 & 0.0440 & -176.47 & 0.0381 \\
\hline & $\tau(5,10,38,37)$ & & 179.29 & 00888 & -179.11 & 0.0890 \\
\hline
\end{tabular}

${ }^{a}$ The numbers are atomic index numbers shown in Figure $1 .{ }^{b}$ Taken from ref. $1 .{ }^{\circ} \mathrm{Hydrogen}$ bond lengths $(r)$ are in $A$ unit, and bond angles $(\theta)$ and torsion angles $(\tau)$ in degree unit.

the $\mathrm{C}-\mathrm{H}$ frequencies of Group $\mathrm{A}$ and $\mathrm{B}$ show anomalous blueshifts of about 68 and $61 \mathrm{~cm}^{-1}$ compared to DMF single. respectively. In contrast, it gives $5 \mathrm{~cm}^{-1}$ of red-shift in group $\mathrm{C}$. The formyl hydrogen atoms at groups $\mathrm{A}$ and $\mathrm{B}$ are in the environments of close contact with others while that of group $\mathrm{C}$ is free from direct contact with other atoms. The subtle interplay between electrostatic attraction and steric repulsion was suggested to be responsible for blue shift effects in $\mathrm{C}-\mathrm{H}^{\cdots}$ Y interactions. This mechanism of the blue shift of the $\mathrm{C}-\mathrm{H}$ stretching frequency suggests that the effect could be enhanced by sterically induced compression of the $\mathrm{C}-\mathrm{H} \cdots$ Y bridging which may arise in the case of intramolecular contacts.

While the out-of-plane deformation (v26) does not show any noticeable splitting the in-plane bending (v1l) shows a negative splitting of $-9 \mathrm{~cm}^{-1}$ for group A. During the in-plane bending of $\mathrm{C}-\mathrm{H}$ bond in group $\mathrm{A}$, two hydrogen atoms move each other head-on in the in-phase mode (Raman active). whereas the two lean to one side in the out-of-phase mode (IR active). This also could be interpreted as the repulsive potential effect caused by steric repulsive interactions.

Vibrations of $\mathbf{C}-\mathrm{N}$ stretching region: Stretching frequencies $(v 13, v 16)$ of $\mathrm{C}-\mathrm{N}$ bonds are fairly localized except the $\mathrm{Cl}-\mathrm{N}$ stretching. The stretching frequencies (vll) of $\mathrm{Cl}-\mathrm{N}$ bonds among three groups are up-shifted compared to the DMF single. indicating that intermolecular interaction makes it shorter and stronger particularly for group $\mathrm{A}$ and $\mathrm{B}$. This bond are strongly: coupled to the $\mathrm{C}=\mathrm{O}$ bond to form amide I band, so this mode is dispersed in several bands. Two modes $v 13$ and are contributed mainly to anti-symmetric and symmetric stretching of $\mathrm{N}-\mathrm{C}$ bonds, respectively. Both are down-shifted compared to the DMF single. These stretching frequencies did not show any significant NCE.

Vibrations of methyl $\mathrm{C}-\mathrm{H}_{3}$ stretching and deformation region: Stretching frequencies $(\mathrm{v} 1 . \mathrm{v}, \mathrm{v} 3, v+, v 20, v 21)$ of $\mathrm{C}-\mathrm{H}_{3}$ bonds are localized. Anti-sy mmetric stretching (vl) of $\mathrm{C}^{-} \mathrm{H}_{3}$ bonds syn to oxygen atom holding A' sy mmetry is spread out widely in the range of $15 \mathrm{~cm}^{-1}$ due to the steric interaction, but others not. Bending $\left(v 7, v 8, v^{9}, v 10, v 22, v 23\right)$ and rocking $(v$ $14, v 15, v 24, v 25)$ of the $\mathrm{C}-\mathrm{H}_{3}$ bonds are also fairly localized except $v 7$ and $v 15$. The anti-synmetric bending $(v 7)$ and inskeletal plane rocking (v15) deformations show moderate positive $\Delta \omega$ values of $2 \mathrm{~cm}^{-1}$ and $9 \mathrm{~cm}^{-1}$ for group $A$ only, respectively. This mode is combined in minor extent with skeletal stretching of delocalized $\mathrm{C}_{2}-\mathrm{N}-\mathrm{C}=\mathrm{O}$ entity of group $\mathrm{A}$.

Vibrations of skeletal in-plane bending region: Bending frequencies $(v 17 . v 18 . v 19)$ of frame entity $\mathrm{C}_{2}-\mathrm{N}-\mathrm{C}=\mathrm{O}$ are slightly delocalized in the negative way. When the skeletal frame of $\mathrm{N}-$ $\mathrm{C}=\mathrm{O}$ in group $\mathrm{A}$ is doing a bending motion in the cases of $\mathrm{v}_{17}$ and $v 19$, the orientation angle of two $\mathrm{C}=\mathrm{O}$ bonds changes continuously in-phase. It could be understood that it perturbs the intermolecular interaction to show moderate negative splitting in the skeletal in-plane bending of group A.

Vibrations of skeletal out-of-plane deformation and torsion region: The torsion and skeletal out-of-plane deformation modes $(v 27 . v 28, v 29 . v 30)$ were mixed together. The torsion mode (through $\mathrm{Cl}-\mathrm{N}$ bond) of $\mathrm{v} 27$ is only split to give positive $\Delta \omega$ value of $6 \mathrm{~cm}^{-1}$ for group A. The in-phase motion (Raman active) of two torsions through $\mathrm{Cl}-\mathrm{N}$ bond in group A looks like a twist motion (consequently no dipole derivative) of methy lene hydrogen atoms, and the out-of-phase motion (IR active) like a wagging motion (consequently small fluctuation of dipole) of those two. This difference induces the splitting of 127 mode because the wagging is usually higher in frequency than the twisting motion.

Force constants of hydrogen bonding in local symmetyy coordinate. The optimized structural parameters and calculated force constants in local symmetry coordinates of hydrogen bonding in DMF hexamer cluster using BP86 and B3LYP are shown in Table + along with crystal structural parameters available. Although the results of two methods are not much 
different from another. the force constants calculated from BP86 functional are discussed as following because the calculated spectra using the functional $\mathrm{BP} 86 / 6-3 \mathrm{I}+\mathrm{G}^{* *}$ fits well the experimental infrared and Raman spectra compared to results of B3LYP functional.

Stretching of hydrogen bonding: Force constants of slightly bent ( 160 degree) and near (less $2.4 \AA$ ) $\mathrm{H} \cdots \mathrm{O}$ bonds (H18 $\cdots$ $\mathrm{O} 2$ and $\mathrm{O} 38 \cdots \mathrm{H} 10$ ) which were drawn with dashed lines in Figure 1 , came out to 0.081 and $0.1084 \mathrm{mdy} n / \mathrm{A}$. For further bent ( 140 degree) and a little further apart (no less $2.5 \AA$ ) $\mathrm{H} \cdots$ $\mathrm{O}$ bonds show $\mathrm{n}$ with dashed lines. $\mathrm{O}+\cdots \mathrm{H} 55$ and $\mathrm{H}+3 \cdots \mathrm{O} 62$. they were calculated to 0.055 and $0.0693 \mathrm{mdyn} / \AA$. These values are about one fourth of strong hydrogen bonding chemical system. It is more than one half the stretching force constants 0.125 mdy $n / \hat{A}$ of $\mathrm{C}=\mathrm{O} \cdots \mathrm{H}-\mathrm{N}$ in the polyglycine peptide system. ${ }^{11}$ This outcome is quite similar to the result previously reported for DMF dimer sy'stem ${ }^{*}$ where roughly one-half the strength of the $\mathrm{C}=\mathrm{O} \cdots \mathrm{H}-\mathrm{N}$ hydrogen bond was calculated. These values are quite comparable to $0.0582 \mathrm{mdyn} / \hat{A}$ observed from a hy'drogen-bonded dimer ${ }^{79}$ formed between trimethy lamine and acetylene, $\left(\mathrm{CH}_{3}\right)_{3} \mathrm{~N} \cdots \mathrm{HC} \equiv \mathrm{CH}$, in gas phase by Fourier-transform microwave spectroscopy. The distance of the hy'drogen bond is similar to $2.4 \AA$ calculated in the hydrogen bonded system ${ }^{3(1}$ of ammonia-acetylene dimer. $\mathrm{H}_{3} \mathrm{~N} \cdots \mathrm{HC} \equiv \mathrm{CH}$.

In-plane bending of hydrogen bonding: Force constants of the in-plane bending of hydrogen bonding $\mathrm{C} 13-\mathrm{H} 18 \cdots \mathrm{O} 2$, which is quite crowd sterically than others. shows $0.551+$ mdyn $\AA$. However. other three bending motions give values in the range of $\sim 0.3 \mathrm{mdy}$ 'n $A$. These are about one half of usual bending force constants observed in typical methyl group, but are quite large compared to 0.030 mdyn $\AA$ of $\mathrm{C}=\mathrm{O} \cdots \mathrm{H}-\mathrm{N}$ bending force constants ${ }^{3.1}$ obtained from the calculation of crystalline antiparallel chain pleated sheet polyglycine I system. However, the bending force constants of weakly bound dimers in the gas phase ${ }^{32}$ were obtained for a series of dimers, A $\cdots B$ (A: symmetric top. B: linear). For the dimer of $\mathrm{H}_{3} \mathrm{~N} \cdots \mathrm{HCN}$. it was calcullated to $\sim 94 \times 10^{-21} \mathrm{~J}$ from the gas phase nuclear quadrupole coupling constants. This comesponds to a value of $\sim 0.094 \mathrm{mdy} n \AA$. Because the hexamer structure has been connected each other through hydrogen bonding with next molecules in the cluster. these in-plane bending modes seem to be very rigid. Further. it has much heavier than small molecules. Recent study ${ }^{33}$ of 15 base pair oligomer of single stranded nucleic acid fragments showed that the bending by $90^{\circ}$ requires roughly $5 \mathrm{kcal} \mathrm{mol}^{-1}$ where the effective bending force constants of $0.02 \sim 0.06$ $\mathrm{kcal} \mathrm{mol}{ }^{-1}$ degree ${ }^{-\hat{*}}$ was reported. This corresponds to roughly $0.46-1.4 \mathrm{mdynA}$ which is yet very huge in fact.

Torsion of hydrogen bonding: Force constants of torsion modes of weakly bent hydrogen bonding came out about 0.09 mdyn $\AA$. but of further bent hỵdrogen bonding to about 0.04 mdynA. These values are also several times larger than the usual torsion force constants adapted in the analy sis of polyglycine I sy'stem. This is also mainly due to the rigidity in the hexamer cluster.

\section{Conclusions}

The equilibrium stnicture. the stabilization energies. and the vibrational properties were studied using a hexamer cluster of DMF molecules. Stabilization free energy for a hexamer fonmation was calculated to about $-40 \mathrm{~kJ} / \mathrm{mol}$ using B3LYP/ $6-3 \mathrm{I}+$ $\mathrm{G}^{* * *}$ and $\mathrm{BP} 86 / 6-31+\mathrm{G}^{* *}$ theory. This inplies that DMF molecules in a condensed phase operate very strong intermolecular interactions. The interactions in bulk could be electrostatic. dipole-dipole or dispersive interaction. These nonbonding interactions are supposed to happen cooperatively through hydrogen atoms in bulk. This can be understood as weak or soft intermolecular hy'drogen bonding a type of $\mathrm{C}-\mathrm{H} \cdots \mathrm{O}$ which can be regarded responsible partly for the hexamer cluster stabilization. Using the force constant matrix calculated for hexamer. vibrational analysis shows successful to explain the experimental Raman and infrared spectra of DMF liquid state. Noncoincidence in Raman and infrared frequencies of amide I band observed experimentally in the liquid state was interpreted in tenns of intermolecular vibrational coupling of dipoles. This supports certain degree of ordering in the liquid state of DMF. The stretching and angle-bending force constants of intermolecular hydrogen bonds $\mathrm{C}-\mathrm{H} \cdots \mathrm{O}$ were considerable to the extent that could not be neglected.

Acknowledgments. This work was supported by the research grant of the Chungbuk National University in 2007.

\section{References}

1. Bormann, H.; Persson, I.: Sandstrom, M.; Stalhandske, C. M. V. J. Chem. Soc. Pewhin Trans. 2000, 2, 393.

2. (a) Stallhandske, C. M. V.: Mnkmm, I.: Sandstrom, M.: Papai, I.) Iohansson, P. Iib. Spectrosc. 1997, 14, 207. (b) Durgaprasad, G.: Sathyanarayana, D. N.; Patel, C. C. Bull. Chem. Soc. Jpn. $1971,4+316$

3. Zhou, X.; Krauser, T. A.; Tate, D. R.; VanBuren, A. S.; Clark, J. A.; Moody, P. R.; Liu, R. J. Phys. Chem. 1996, 100, 16822.

4. (a) Radnai, T.: Itoh, S.; Othaki, H. Bull. Chem. Soc. Jpn 1988. 61, 3845. (b) Othaki, H.; Itoh, S.; Rode, B. M Bull. Chent. Soc. Jpn. 1986, 59, 27l. (c) Othaki, H.; Itoh, S.; Yamaguchi, T.; Ishigro, S.; Rode, B. M. Bull Chem. Soc. Jpm 1983, $56,3406$.

5. Schultz, G.; Hargitti, I. J. Phws. Chem. 1993, 97, 4966.

6. Cordeiro, I. M. M. Inter. J. Onan. Chem. 1997, 65, 709.

7. Miyake. M.: Kaji. O.: Nakasawa, N.: Suzuki. T. J. Chem. Soc., Farndav Trans. $21985,81,277$.

8. Varoas. R.: Garza T.: Dison. D. A.: Hay. B. P. J. Am Chem. Soc. $2000,122,4750$

9. Kim, K. H.; Kim, Y. Bull. Kowan Chem. Soc. 2007, 28, 2454.

10. Desiraju, G. R.; Steiner. T. The Heak Hydrogen Bond in Smictural Chemistiv and Biologv, Oxford University Press: Oxford and New York, 1999

11. Lee, S.-H.; Palmo, K.: Krimm S. J. Comput. Chem. 1999, 20. 1067.

12. Lee, C.; Park, S.-K; Lee, Min, K.-C.; Kim, Y.; Lee, N.-S. Bull. Korean Chem. Soc. 2008, 29, 1951

13. Giorgini, M. G.; Musso, M: Asenbaum, A.; Doge, G. Mol. Phys. $2000,98,783$

14. (a) Kirillov, S. A J M Iol Liq. 2004, 110,95, (b) Giorgini, M. G. Plow Appl. Chem. 2004, 76, 157

15. (a) Musso. M.: Gioroini. M. G.: Torii. H.: Dorka. R.: Schiel. D.: Asenbaum, A.; Kentel, Z.: Oehme, K.-L. J. Mol Liq 2006, 125, 115. (b) Torii, H.; Musso, M.; Giorgini, M. G.J. Phws Chent A $2005,109,7797$.

16. Tori, H. J. Phus Chem. B 2007, 111, 5434

17. (a) Torii, H. I. Phys Chem. A 1999, 103, 2843 (b) Musso, M: Toni, H.: Ottaviani, P.: Asenbaum, A.: Giorgini, M. G. J. Ploss. Chem. A 2002, 106, 10152 
18. (a) Tonii, H. J. Phvs Chem at 2006, 110, 4822 (b) Torii, H. Chem. Phys. Lett $2005,414,417$.

19. Dub, P. A.; Filippov, O. A.; Belkova, N. V.; Rodriguez-Zubiri, M.; Poli, R. J. Phys. Chem . $12009,113,6348$.

20. Mrshakina, N. S. Asher, S. A. J. Phws. Chem. B 2007, 111, 4271.

21. Meic, Z.: Baranovic, G.: Smrecki, V.: Novak, P.: Keresztury, G.; Holly, H. J. Mol. Str: 1997, 408409,399

22. Michalska, D.: Bienko, D. C.: Czaniik-Matusewicz, B.; Wierzejewska, M: Sandorfy, C.; Zeegers-Hurskens, Th. J. Phws. Chem. B 2007, 111,12228 .

23. Jablonski, M. J. Hol. Strtict. (Theochem) 2007, 820, 118

24. Katsumoto, Y.; Komatsu, H. Ohuno, K. J Am. Chem. Soc. 2006, 128,9278

25. Xu, Z: Li, H: Wang, C: Wu, T.; Han, S. Chem. Phus. Lett 2004,
394. 405

26. Biliskov, N.: Baranovic, G. J. Mol. Liq. 2009, 14t, 153.

27. Xu, Z.: Li, H.: Wang. C.: Pan, H.: Han, S. J. Chem. Phes. 2006. 124,244502 .

28. Lei, Y: Li, H.; Pan, H.: Han, S. J. Phw. Chem. A 2003, 107, 1574.

29. Legon, A. C.: Rego, C. A. J. Mol. Struct. $1988,189,137$.

30. Hartmann. M.: Radom. L. J. Phss Chem it 2000. 104. 968.

31. Moore, W. H.; Krimm, S. Proci Kat .Acad. Sci. LS.4 1975, 72 , 4933.

32. (a) Legon, A. C., Lister, D. G. J. Mol. Strict 1996, 382, 63. (b) Legon, A. C.: Cope, P.: Millen, D. I. J. Chem. Soc., Perkin Trans. $1986,82,1189$.

33. Curuksu, J.; Zacharias, M.; Lavery, R.; Zakrzewska, K. Nicteic Acids Res. 2009, 37, 3766 . 